\title{
The Effect of HIV and Art on the Development of Hypertension and Type 2 Diabetes Mellitus
}

\author{
Thokozani SB Maseko $^{1^{*}}$ and Sakhile KS Masuku ${ }^{2}$ \\ ${ }^{1}$ Research Unit, International Centers for AIDS Care \& Treatment Programmes, Swaziland \\ ${ }^{2}$ Department of Community Health Nursing Science, University of Swaziland, Swaziland
}

*Corresponding author: Thokozani SB Maseko, Research Unit, International Centers for AIDS Care and Treatment Programmes, Swaziland, Tel: +268 76254021; Email: tsb139099@gmail.com

Received date: February 28, 2017; Accepted date: March 16, 2017; Published date: March 20, 2017

Copyright: (c) 2017 Maseko TSB, et al. This is an open-access article distributed under the terms of the Creative Commons Attribution License, which permits unrestricted use, distribution, and reproduction in any medium, provided the original author and source are credited.

\begin{abstract}
Diabetes mellitus and hypertension [DM] are among the major causes of morbidity and mortality among people living with human immunodeficiency virus [PLHIV]. Diabetes mellitus alone is associated with morbidities that consequently reduce life expectancy and quality of life, and causes demoralising complications inclusive of ischaemic heart disease, stroke, blindness and peripheral vascular disease. Hypertension is an important and treatable cause of cardiovascular morbidity and mortality. It is an independent risk factor for myocardial infarction, chronic kidney disease ischemic and haemorrhagic stroke, heart failure and premature death. HIV infection is associated with morbidities that consequently reduce life expectancy and quality of life. There is a perceived link between HIV infection and DM and hypertension. This is a scoop review of studies on the link between HIV and DM and hypertension, that is, both epidemiologic and biological evidence to date. The literature review shows that the incidence and prevalence of type 2 diabetes [T2DM] is higher among PLHIV on ART compared to the HIV negative population. Being infected by human immunodeficiency virus (HIV) is implied to trigger an inflammatory response that, in turn, results in insulin resistance, a risk for T2DM. HIV is linked to hypertension through alterations in triglycerides, T cells and angiotensin II as well as the aggressive use of ART. The roll out of antiretroviral therapy (ART), as means to combat HIV, has benefits for PLHIV, inclusive of increased survival and living longer; yet older age is associated with hypertension and T2DM. The side effects of ART and long term use of ART are implicated in increasing the risk of T2DM among PLHIV. The co-occurrence of HIV, hypertension and T2DM in developing countries presents an overload to the burden of diseases because these countries are already experiencing high prevalence rates of HIV thereby complicating the health status of the population. Notwithstanding the contrasting research reports on the link between HIV, hypertension and DM hypertension and DM among PLHIV is a cause for concern, and there is a need for more studies, particularly in areas most hit by HIV.
\end{abstract}

Keywords: HIV; Antiretroviral therapy; Diabetes mellitus; Hypertension; People living with HIV; Type 2 diabetes

\section{Global Burden of HIV Infection}

For the past three decades, human immunodeficiency virus (HIV) infection has remained a major global public health concern. Morbidity and mortality rates have continued to negatively impact the life expectancy of many developing and underdeveloped nations. On estimation, about 35 million people live with HIV globally [UNAIDS, 2014]. Of the global HIV prevalence rate, about $67 \%$ comes from subSahara African region, and this region accounts for $72 \%$ of the world's HIV related mortality [1]. For instance, in Swaziland, one of the subSaharan African countries, from the first HIV reported case in 1986, HIV has been rampantly spreading throughout the population [2], to the current prevalence rate of $26 \%$ in the reproductive age group of 15-49 years [3]; and among pregnant women receiving antenatal care [ANC], HIV infection has been steadily increasing from 3.9\% in 1992 to $41.1 \%$ in 2010 [4].

HIV has also had overwhelming negative effects on various countries, on both the economy and development. For instance, in Swaziland life expectancy decreased to 48 years, enlisting it among the lowest in the world; and orphaned and vulnerable children [OVC] were estimated at 104,026 in 2010 [5]. HIV also threatens food security
$[6,7]$ because of the increased demand of agricultural produce explained by the cyclical relationship between HIV and nutrition [8]; yet agricultural activities may be deserted due to ill health. For agroeconomy countries, such as Swaziland, poverty is worsened [9], and socio-economic gains reverse [10], putting a question to the long-term survival of such countries [11]. Poverty, unemployment and food security exacerbate the rates of HIV transmission [12], hence the need to combat HIV.

\section{Response to HIV}

In an effort to mitigate HIV and its effects, various countries have embarked on extensive use of antiretroviral [ARV] drugs. Globally, HIV testing and counselling and access to antiretroviral therapy (ART) have been scaled up. Between 2009 and 2011, an increase of $63 \%$ in universal ART access has been recorded [13]. Consequently, an estimated 8 million people were on ART in 2011, a steady increase continued and currently more than 9.7 million PLHIV have been initiated on ART [14]. Antiretroviral therapy, sometimes used synonymously with highly active ART (HAART), refers to the use of a combination of three or more antiretroviral drugs [ARVs] to achieve viral suppression while ARVs refer to the actual anti-HIV medicines [15]. To scale up ART access, the World Health Organisation [WHO] has been modifying and improving ART guidelines. Initially, the guidelines provided guidance for HIV infected adults and for 
prevention of mother to child transmission [PMTCT] of HIV [16]. In 2006, the guidelines were updated to incorporate a concept of public health [17]. In 2010, further modifications to include the aspect of CD4 count, $<200$ cells $/ \mathrm{mm} 3$, at which ART should be initiated and was later changed to a CD4 count of $<350$ cells $/ \mathrm{mm}^{3}$. Recently, in 2013, the CD4 count of ART initiation was changed to $500 \mathrm{CD} 4$ cells $/ \mathrm{mm}^{3}$ [18]. Recently, a new program, 'test and start' [19], has been initiated in many countries, whereby ones'CD4 cell count is no longer used as a parameter to initiate one on ART, but their HIV positive status. The aim is to enroll as many PLHIV as possible into ART. In Swaziland, this program was initiated in October 2016 and is implemented in all ART initiating health facilities [20].

These changes have and still are profoundly increasing the proportion of PLHIV on ART. For instance, in Swaziland by December, 2010, about 78919 of the $220000 \mathrm{HIV}$ infected persons were initiated on ART, of whom 49371 were women [21], and now Swaziland is among the Sub-Saharan African countries with $80 \%$ ART coverage [22], and $83 \%$ among pregnant women [23]. ART has also vividly reduced HIV related morbidities and mortalities [24], and life expectancy among people living with HIV [PLHIV] has increased [25].

HIV care has also been modified to cover opportunistic infections, particularly tuberculosis [TB]. Consequently, much effort has been focused in integrating TB and HIV care for PLHIV, with success. This implies that various countries are heading towards a favourable position towards eliminating Acquired Immune Deficiency Syndrome [AIDS] and reducing new HIV infections. PLHIV are therefore likely to live longer albeit they are HIV positive. The rollout of ART increases survival of PLHIV which is in line with the 90/90/90 Joint United Nations Program on HIV/AIDS [UNAIDS] targets for the end of AIDS campaign [25]. However, as the number of people on ART increases, the age of PLHIV also increases, raising concerns such as the coexistence of HIV with non-communicable diseases [NCDs]. This suggests the importance of monitoring the incidence of NCDs such as diabetes mellitus, hypertension and other cardiovascular related conditions in addition to access, adherence and retention to treatment among PLHIV.

Albeit there is progress in combating HIV and integrating TB and HIV care, there has been an increment, particularly in developing countries, in the incidence of non-communicable diseases including diabetes mellitus, high blood pressure and cardiovascular diseases. In the same vein, diseases such as peripheral neuropathy, mental disorders, type 2 diabetes mellitus [T2DM], hepatitis, kidney disease, lung disease, gastrointestinal disease, AIDS-related cancers and neurological diseases have become non-communicable diseases of concern in HIV infection and rollout of ART [26].

\section{Diabetes Mellitus}

Diabetes mellitus [DM] is one of the most important noncommunicable diseases of public health concern in both developed and developing countries and is apparently dynamic. The global prevalence of diabetes in 2013 was 382 million people and is projected to increase to 592 million in 2035 [27]. These projections of DM are likely to intensify in the developing world secondary to, in part, HIV and ART, and the noticeable revolution of lifestyles in these countries [28].

DM is defined as a collection of disorders relating to metabolism that manifest by increased levels of glucose in the blood, subsequent to malfunction in either insulin secretion or action [29]. These metabolic disorders are often a consequence of autoimmune-mediated destruction of beta cells in the pancreas thereby leading to decreased insulin secretion [30] or can be secondary to abnormalities in the action of insulin [type 2 diabetes mellitus]. Of all DM cases globally, T2DM accounts for about $90 \%$, and the remaining $10 \%$ is attributable to type 1 diabetes mellitus [31]. The mechanisms through which type 2 diabetes mellitus [T2DM] develops relate to insulin resistance, adipose tissue [entails free fatty acids], tumour necrotic factor-alpha [TNF- $\alpha$ ], Peroxisome proliferator activated receptor gamma [PPAR $\gamma$ ], interleukins, fuel oxidation, insulin secretion dysfunction, pancreas beta cells dysfunction and glucotoxicity [32]. In line with WHO standards, DM is diagnosed when a person has fasting plasma glucose [FPG] of $\geq 7.0 \mathrm{mmol} / \mathrm{L}$ glucose and a fasting 2-hour plasma glucose following administration of $75 \mathrm{~g}$ oral glucose $\geq 11.1 \mathrm{mmol} / \mathrm{L}$ [WHO, 2006]. According to these standards, DM should be differentiated from impaired glucose intolerance [IGT], which is when a person has FPG ranges of $\geq 7.8$ to $<11.1 \mathrm{mmol} / 1$ measured 2 hours post ingestion of 75 $\mathrm{g}$ oral glucose [WHO, 2006]. The focus of this review is T2DM and hypertension.

$\mathrm{DM}$ alone is associated with morbidities that consequently reduce life expectancy and quality of life. It causes demoralising complications inclusive of ischaemic heart disease, stroke, blindness as well as peripheral vascular disease [33]. Several studies identified DM risk factors as heredity, diet and level physical activity [Currier et al. 2008; Ebrahim et al. 2013b; Gillett et al. 2012], but there is growing evidence that there is link between HIV and T2DM [34-38]. The molecular events resulting from HIV infection and exposure to ART are similar to those that lead to diabetes [39], hence the link between HIV and the risk for diabetes.

\section{Hypertension}

Hypertension is a global issue and has led the World Health Organization to declare that suboptimal blood pressure is the leading risk for death in women and the second leading risk for death in men in developed countries [40,41]. Hypertension refers to an elevated blood pressure. It is an important and treatable cause of cardiovascular morbidity and mortality. Hypertension is an independent risk factor for myocardial infarction, chronic kidney disease, ischemic and haemorrhagic stroke, heart failure and premature death. Pharmacologic treatment should be initiated when the systolic pressure is $140 \mathrm{~mm} \mathrm{Hg}$ or higher, or when the diastolic pressure is 90 $\mathrm{mm} \mathrm{Hg}$ or higher. The target systolic pressure is less than $140 \mathrm{~mm} \mathrm{Hg}$, and the target diastolic pressure is less than $90 \mathrm{~mm} \mathrm{Hg}$ [42]. Although the World Health Organization has recommended that treatment and control of hypertension is a global health priority, there is no consensus on how this should be accomplished [43]. There is substantial evidence that physicians frequently do not follow hypertension management guidelines and that current physician practice patterns represent a major barrier to the treatment and control of hypertension [44-47].

\section{HIV, diabetes mellitus and hypertension}

The prevalence of DM and hypertension among PLHIV makes these conditions non-communicable disease of concern. DM prevalence in HIV infected people ranges from 2-14\% [48]. The co-occurrence of DM and hypertension in HIV is becoming a threat to public health, especially in developing countries, lately. Back in 2000 and 2003, the correlation between HIV and DM was negative: $[\mathrm{r}=-0.434, \mathrm{p}<0.001]$ and $[\mathrm{r}=-0.281, \mathrm{p}=0.02]$, respectively $[49,50]$. However, a persistent 
increase in the prevalence of HIV and DM has since been observed as of 2007 [ $\mathrm{r}=0.346, \mathrm{p}=0.004]$ and 2010 [r=0.440, $\mathrm{p}<0.001]$ [51,52].

The above findings support that DM and hypertension are emerging NCDs in HIV infection and demand attention from countries with high prevalence rates of HIV infection. The intensification of DM and hypertension in HIV infection contributes to the transition of HIV from being an acute condition to a chronic condition and implies a link between these conditions.

Various studies have reported the link between HIV, hypertension and T2DM to be inherent in HIV infection itself, adverse effects of ART and long-term use of ART, in addition to lifestyle, genetics and aging [53]; but there is contrasting evidence whether HIV infection itself predisposes one to T2DM and hypertension or not.

\section{HIV and T2DM}

The major implicated way through which HIV predisposes one to T2DM is through the inflammatory response process occurring during HIV infection. Infection with HIV results in increased inflammatory markers. Inflammatory markers related to HIV infection have been implicated as causally associated to premature onset of chronic diseases [54], and T2DM and hypertension are some of the chronic diseases predicted by inflammatory markers in HIV infection [55]. The commonly identified inflammatory markers in HIV infection include interleukin-6 [IL-6], and sensitivity C-reactive protein [hsCRP] and have been reported to be higher among those who developed T2DM compared to those who did not: 3.45 versus $2.50 \mathrm{pg} / \mathrm{mL}$ for IL- 6 and 4.91 versus $3.29 \mu \mathrm{g} / \mathrm{mL}$ for hsCRP, both $\mathrm{p}<0.001$ (Dooko, 2014). Individuals infected with HIV are also reported to have significantly higher levels of d-dimer and cystatin $\mathrm{C}$ inflammatory biomarkers compared to those not infected [56,57].

More studies have alluded to that HIV infection predispose one to diabetes. There is observed higher incidence of diabetes in HIV infected people compared to the non-HIV infected [58]. About half of HIV infected people can develop diabetes [59], and diabetes can be diagnosed even among patients newly infected with HIV, not on ART $[60,61]$.

On another note, other studies have provided contrasting evidence. Some studies have reported a higher prevalence of diabetes in the general population compared to HIV infected people [62] while other studies reported that there are other risk factors, other than HIV infection alone, that lead to diabetes. These include being pre-diabetic at the time of HIV infection [63], having other HIV related opportunistic diseases such as TB [64], and having elevated levels of glaciated haemoglobin [A1C] (Tien et al. 2012); hence HIV alone is argued to be associated with a lower risk of DM at baseline [65]. These studies hold that other factors other than HIV infection alone influence the development of diabetes among PLHIV [66].

Therefore, the direct influence of HIV on diabetes remains unclear. It is argued that other factors relating to HIV underlie the likelihood for DM to develop, yet the extent to which traditional factors may influence the development of DM in HIV infected and uninfected persons remains controversial and demands more studies to be conducted, especially in countries with a high prevalence of HIV. The above mentioned studies also suggest that TB could be a confounder of diabetes hence more studies that will determine the prevalence of DM stratified by TB infection are needed, particularly in the African context where HIV/TB co-morbidity is common, but such studies are scarce. On another note, there are few studies in the sub Saharan region reporting on the prevalence of DM in HIV infected patients yet this region is hard hit by HIV. Another constraint of most of the aforementioned studies was lack of national representativeness; hence more studies looking at the prevalence of DM among HIV infected persons are needed, otherwise it remains questionable that HIV infection directly influences the development of diabetes, and those countries with high HIV prevalence rates need a model of care pertaining diabetes among PLHIV.

\section{Diabetes mellitus and ART}

Antiretroviral therapy has been implicated in the development of diabetes among PLHIV. Diabetes incidence and prevalence has been reported higher among PLHIV on ART compared to the HIV negative population [67]. Studies conducted in Africa also reported an increase in the prevalence of diabetes among PLHIV and on ART for years [68]. Antiretroviral therapy and longer exposure to ART are associated with diabetes related metabolic syndrome [69]. In fact, diabetes prevalence is 5-9 fold higher in PLHIV with metabolic syndrome [70].

Generally, the adverse effects of ART and long-term use of ART are implied to trigger body mechanisms that lead to development of T2DM. Antiretroviral therapy is implicated in the development of metabolic changes related to fat distribution and glucose homeostasis [71]. Introduction of ART to the body leads to increased levels of TNF$\alpha$, which, in turn, impairs metabolism of fatty acids and lipid oxidation, resulting in suppressed lipolysis [72]. This, in turn, results in altered fat distribution, and subsequent changes in lipid profile, evident in an observed increase in the levels of triglycerides and low density lipoprotein [LDL] cholesterol, and a decrease in high density lipoprotein [HDL] cholesterol [73].

Since early 19th century, increased triglycerides [hypertriglyceridemia] have been associated with poor virological control [74], implying a subsequent difficulty for the body to control viral infection with HIV; yet this process leads to further increased levels of TNF- $\alpha$ [75-77]. This suggests that the interaction between TNF- $\alpha$, hypertriglyceridemia, and poor viral infection control is cyclical. Hypertriglyceridemia ultimately results in insulin resistance [78], a risk factor for T2DM. Insulin resistance develops as a result of ART binding to the insulin sensitive glucose transporter [GLUT 4] causing blockage [79].

Antiretroviral therapies further inhibits differentiation of adipocytes and hinder polymerase- $\gamma$, with a subsequent mitochondria dysfunction [80]. Protein inhibitors [PI], which are the main cause of adipocytes differentiation inhibition, alter the expression of sterol regulatory element-binding protein-1 [SREB-1] and peroxisome proliferator-activated receptor- $\gamma$ [PPAR- $\gamma]$, which are inevitably necessary for differentiation of adipocytes [81]. Hindrance of polymerase $-\gamma$ coupled with drain of mitochondrial deoxy nucleic acid [DNA], termed mitochondrial toxicity, both caused by nuclear reverse transcriptase inhibitors [NRTIs], are also implicated in the development of diabetes among PLHIV on ART [82]. Both mitochondria dysfunction and adipogenesis result in insulin resistance and subsequent development of diabetes as summarised in Figure1.

Protein inhibitors and NNRTI are also implicated in causing lipodystrophy and dyslipidaemia [83]. Lipodystrophy, a clinical manifestations of metabolic syndrome, is a complex syndrome thought to be a secondary effect of HIV infection, direct drug-induced toxicities and the indirect effects of lipid metabolism changes [84]. Dyslipidaemia, a metabolic disorder, is characterised by 
hypertriglyceridaemia, hypercholesterolemia and low levels of high density lipoprotein [85], and results from erroneous metabolism of lipoprotein [86]. Hypertriglyceridaemia has been found to be associated with acute pancreatitis [87], a potential for altered function of the beta cells in the pancreas and subsequent development of diabetes.

Dyslipidaemia and lipodystrophy have been reported to be severe and prevalent with ART use [88]. Protein inhibitors such as ritonavir have been reported to cause a striking increase of triglycerides in less than six months post ART initiation [89]. Some studies have reported some ARVs that are associated with dysfunctional metabolism: nevirapine, stavudine, lamuvidine [90], efavirenz [91] indinavir, saquinavir, didanosine [92] and zidovudine [93]; yet some studies reported that both hypertriglyceridaemia and hypercholesterolemia have been observed among HIV positive patients on ART regardless of regime [94]. This implies that all ART regimes may not completely spare HIV infected patients from metabolic disorders and the subsequent risk of diabetes. In fact, wohl concluded that the antiretroviral drug that causes the most severe accumulation of visceral fat is unknown. Therefore, even with reviewed ART regimes, the need to monitor patients on ART for development of diabetes cannot be over emphasised, particularly in the era of universal ART access.

Albeit there are other factors associated with development of diabetes such as gender - being male [95], obesity, poor dietary habits, heredity and physical inactivity [96], and age [97], the evidence that ART is associated to diabetes cannot be refuted.

Even though plausible similarities have been reported in the hypothesised link between DM, HIV and ART, certain controversies exist. Some studies have reported higher prevalence of diabetes among women [98] while others among men [99] infected with HIV. Contrary to the high diabetes prevalence among PLHIV [100], some studies reported a lower prevalence among the HIV positive population compared to HIV negative population. These controversies warrant more studies to be undertaken [101].

\section{HIV, ART and hypertension}

HIV infection is implicated in the development of hypertension. Presently, the exact mechanism underlying the association between HIV infection and many aging-related chronic diseases remains unknown [102]. HIV infection without ART initiation is associated with significant changes in lipids, hepatic and hematologic biomarkers $[p<0.01]$. Specifically, triglycerides increase [103]. These changes occur without significant changes in BMI, and can happen relatively quickly, that is, 1.8 years, with moderate reduction in median CD4 cell count [104]. This evidence does not only suggests that HIV infection prior to ART initiation is associated with changes in individual risk factors [e.g., serum lipids] but more importantly, that the changes in multiple biomarkers across several organ systems may be indicative of a proinflammatory response [105]. For instance, serum triglycerides, which increase following infection, have been correlated with interferon $\alpha$, a pro-inflammatory cytokine [106] related to chronic cardiovascular conditions including hypertension. If the changes in these biomarkers associated with HIV infection are indicative of an underlying proinflammatory state, it is possible that even with successful ART, the excess risk of end organ disease that is associated with HIV infection may not be completely eliminated. For instance, some studies found that HIV infection followed by ART initiation and HIV-1 RNA of less than 500 copies $/ \mathrm{mL}$ does not reverse alteration in triglycerides and
LDL cholesterol to pre-HIV infection levels [107] hence the risk for hypertension still remains.

Another mechanism through which HIV infection triggers hypertension is through the T lymphocytes response to HIV infection, and the interaction between $\mathrm{T}$ lymphocytes angiotensin II. Angiotensin II is a hormone which is an important mediator of hypertension. It increases thirst, causes vasoconstriction, promotes salt retention by the kidney, and enhances the release of catecholamines from nerves and the adrenal gland [108]. Angiotensin II also directly promotes inflammation and the development of atherosclerosis [109]. HIV infection triggers the body proliferation of $\mathrm{T}$ lymphocytes in the acute phase, and Angiotensin II stimulates T cell proliferation [110]. T lymphocytes contain a functional Nox-based nicotinamide adenosine dinucleotide phosphate [NADPH] oxidases [111] and an AT1 receptor [112]. These are multi-sub-unit enzymes that are similar to neutrophil oxidases found in vascular cells, kidneys, and central nervous system [113] that are responsible for vasoconstriction and salt retention in the kidneys. Angiotensin II can activate these enzymes, and the O2- that is subsequently produced can react with the endogenous vasodilator nitric oxide $[\mathrm{NO}]$ at diffusion-limited rates, thereby promoting vasoconstriction [114]. These Nox enzymes also produce reactive oxygen species [ROS] which have been implicated in several models of experimental hypertension [23]. These processes increases systemic vascular resistance and elevate blood pressure.

Recent studies provided further evidence that certain $\mathrm{T}$ cells are essential for the development of hypertension [10]. The specific subsets of $\mathrm{T}$ cells that are important in hypertension are unknown. Traditionally, $\mathrm{T}$ helper cells are thought to differentiate into distinct subsets as Th1 and Th2 with different functions and patterns of cytokine secretion [6]. An imbalance in Th1/Th2 subsets is implicated in resistance and susceptibility to infection [2], the pathogenesis of autoimmune diseases including diabetes mellitus [8], the development of atherosclerosis [86], and hypertensive kidney disease [6]. More evidence suggests that $\mathrm{T}$ helper cells have a subset that produces a unique cytokine, IL-17 [99] which has been implicated in the pathogenesis of many autoimmune and inflammatory diseases, and evidence supports that IL-17 has a role in cardiovascular diseases [56]. Importantly, IL-17 synergizes with other cytokines, such as TNF- $\alpha$, to modulate inflammatory responses [52], and TNF- $\alpha$ plays a critical role in angiotensin II- induced hypertension, [110] and contribute to the hypertensive phenotype [6].

On another note, HIV infection progression triggers suppression of CD4 counts, and those patients have a low incidence of hypertension [6]. Conversely, the aggressive use of ART to achieve viral suppression also leads to increase in blood pressure through changes in fat metabolism and distribution [22]. This is summarised in Figure 1.

Collectively, these studies suggest that adaptive immunity and ART contributes to the development of hypertension and diabetes, and the mechanisms that take place can lead to a concurrent development of both. Albeit there is plausible research evidence that HIV and ART can lead to hypertension, most of these studies were experimental and invivo. There are limited studies comparing the incidence and prevalence of hypertension between PLHIV and the negative population. There is limited evidence to firmly rule out if hypertension in PLHIV is due to other risk factors other than HIV infection and ART alone. Of note, most studies on the link between T2DM, hypertension and HIV come from high income countries, and those findings cannot be used to infer to the settings in sub-Sahara Africa because of the potential difference in the two settings [113]. Data that feature developing countries 
Page 5 of 8

predominately focus on Latin America, Asian, East and West African countries. Thus far, data reported on sub-Saharan African countries covers few countries to create a clear picture of the burden of diabetes and hypertension in this part of the world, implying a gap in studies focusing on DM and hypertension among PLHIV in sub-Sahara Africa; hence there is a need for data from sub-Saharan Africa to quantify the burden of DM and hypertension among PLHIV as well as quantification of all the factors associated with the risk of hypertension and $\mathrm{T} 2 \mathrm{DM}$ in this group of patients.

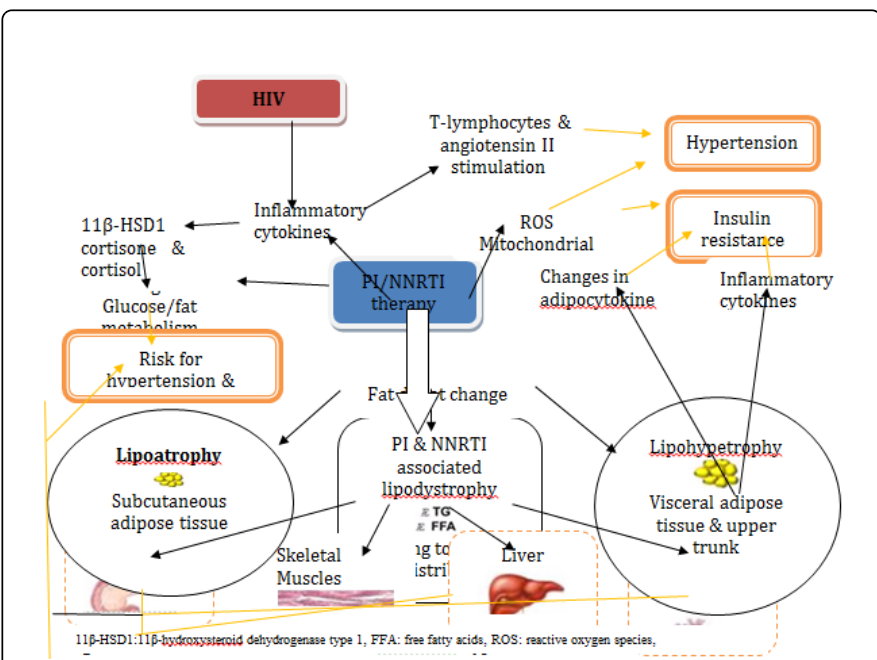

Figure 1: HIV infection progression triggers suppression of CD4 counts.

\section{References}

1. UNAIDS (2014) Global AIDS response progress reporting 2014 Construction of Core indicators for monitoring the 2011 United Nations Political declaration on HIV and AIDS, from Joint United Nations Programme on HIV/AIDS. UNAIDS.

2. MOT (2009) Swaziland HIV Prevention Response and Modes of Transmission Analysis. NERCHA 21: 126.

3. CSO (2008) Swaziland Demographic and Health Survey 2006-07. Central Statistical Office and Macro International Inc.

4. Malik K (2013) Human Development Report 2013 The Rise of the South: Human Progress in a Diverse World. UNDP

5. UNGASS (2010) Monitoring the declaration of commitment on HIV/ AIDS (UNGASS) Swaziland Country Report.

6. Masuku M, Sithole M (2009) The impact of HIV/AIDS on food security and household vulnerability in Swaziland. Agrekon 48: 1-23.

7. Semba, R, Tang A (1999) British Journal of Nutrition 81: 181-189.

8. Juma C, Agwara H (2007) Africa in the global knowledge economy: strategic options. Int J Techn Globalisation 2: 218-231.

9. Whiteside A, Andrade C, Arrehag L, Dlamini S, Ginindza T, et al. (2006) The socio-economic impact of HIV/AIDS in Swaziland. Mbabane, Swaziland: National

Emergency Response Council on HIV and AIDS. NERCHA.

10. USCB (2010) Profile of General Population and Housing Characteristics. Census Bureau

11. NSF (2009) National Multi-sectoral Strategic Framework. National Emergency Response Council on HIV and AIDS.
12. UNAIDS (2012) Global report: UNAIDS report on the global AIDS epidemic 2012. Joint United Nations Programme on HIV/AIDS. UNAIDS.

13. WHO (2013) Consolidated guidelines on the use of antiretroviral drugs for treating and preventing HIV infection: recommendations for a public health approach 14: 26-34.

14. WHO (2002) Scaling up antiretroviral therapy in resource-limited settings. Guidelines for a public health approach. 22: 16-23.

15. WHO (2004) Antiretroviral drugs for treating pregnant women and preventing HIV infection in infants. WHO 21: 29-38.

16. MoH (2012) Swaziland HIV Estimates and Projections report. Mbabane Swaziland Ministry of Health.

17. MoH (2016) Swaziland HIV Care and Management. Mbabane Swaziland Ministry of Health.

18. UNAIDS (2012) UNAIDS World AIDS Day report Joint United Nations Programme on HIV/AIDS.

19. Zhang F, Dou Z, Zhang, Y, Zhao Y, Zhao, et al. (2011) Effect of earlier initiation of antiretroviral treatment and increased treatment coverage on HIV-related mortality in China: a national observational cohort study. Lancet Infect Dis 11: 516-524.

20. Slaymaker E, Todd J, Marston M, Calvert C, Michael D, et al. (2014) How have ART treatment programmes changed the patterns of excess mortality in people living with HIV? Estimates from four countries in East and Southern Africa. Global Health Action.

21. Narayan K, Miotti P, Anand N, Kline L, Harmston C, et al. (2014) HIV and Noncommunicable Disease Comorbidities in the Era of Antiretroviral Therapy: A Vital Agenda for Research in Low- and MiddleIncome Country Settings. J Acquir Immune Defic Syndr 67: S2-S7.

22. Federation I (2013) IDF Diabetes Atlas.

23. Pang T, Guindon G (2004) Globalization and risks to health. EMBO Rep 5: S11-S16.

24. American Diabetes Association (2005) Standards of Medical Care in Diabetes. Diabetes Care 28: S4-S36.

25. Fernandez M (2006) Molecular basis of type-2 diabetes. Molecular Endocrinology 87.

26. Currier J, Lundgren J, Carr A, Klein D, Sabin C, et al. (2008) Epidemiological Evidence for Cardiovascular Disease in HIV - Infected Patients and Relationship to Highly Active Antiretroviral Therapy. Circulation. 118: e29-e35.

27. Ebrahim S, Pearce N, Smeeth L, Casas J, Jaffar S, et al. (2013) Tackling Non-Communicable Diseases In Low- and Middle-Income Countries: Is the Evidence from High-Income Countries All We Need? PLoS Med. 10: e1001377.

28. Gillett M, Royle P, Snaith A, Scotland G, Poobalan A, et al. (2012) NonPharmacological Interventions to Reduce the Risk of Diabetes in People with Impaired Glucose Regulation: A Systematic Review and Economic Evaluation. NIHR Journals Library. 16: 33.

29. Worm S, DeWit S, Weber R, Sabin C, Reiss P, et al. (2009) Diabetes mellitus, pre-existing coronary heart disease, and the risk of subsequent coronary heart disease events in patients infected with human immunodeficiency virus: the data collection on adverse events of anti HIV drugs. Circulation. 119: 805-811.

30. Anuurad E, Bremer A, Berglund L (2010) HIV Protease Inhibitors and Obesity. Curr Opin Endocrinol Diabetes Obes. 17: 478-485.

31. Dooko C (2014) Interleukin-6, high-sensitivity C-reactive protein, and the development of type 2 diabetes among HIV positive patients taking antiretroviral therapy. J Acquir Immune Defic Syndr 67: 538.

32. Haregu T, Elliott J, Setswe G, Oldenbur B (2013) Epidemiological Patterns of HIV/AIDS and Diabetes in Developing Countries: ACluster Analysis. International Journal of Tropical Disease \& Health 3: 1-12.

33. Deeks S (2011) HIV Infection, Inflammation, Immunosenescence, and Aging. Annu Rev Med 62: 141-155.

34. Brown T, Tassiopoulos K, Bosch R, Shikuma C, McComsey G (2010) Association Between Systemic Inflammation and Incident Diabetes in 
HIV-Infected Patients After Initiation of Antiretroviral Therapy. Diabetes Care 33: 2244-2249.

35. Neuhaus J, Jacobs D, Baker J, Calmy A, Duprez D, et al. (2010) Markers of inflammation, coagulation, and renal function are elevated in adults with HIV infection. J Infect Dis. 15: 1788

36. Rasmussen L, Mathiesen E, Kronborg G, Pedersen C, Gerstoft J, et al. (2012) Risk of Diabetes Mellitus in Persons with and without HIV: A Danish Nationwide Population-Based Cohort Study. PLoS One 7: e44575.

37. Butt A, McGinnis K, Barradas M, Crystal S, Simberkoff M, et al. (2009) HIV Infection and the Risk of Diabetes Mellitus. AIDS. 23: 1227-1234.

38. Tien P, Schneider M, Cox C, Karim R, Cohen M (2012) Association of HIV infection with incident diabetes mellitus: impact of using hemoglobin $\mathrm{AlC}$ as a criterion for diabetes. J Acquir Immune Defic Syndr. 61: 334-340.

39. Domo G, Wunamir J (2015) Prevalence Of Diabetes Mellitus Among HIV Positive Patients Attending General Hospital Mubi, Adamawa State. J Nov A ppl Sci 4: 13-17.

40. Shen Y, Wang Z, Liu L, Zhnag R, Zheng Y (2013) Prevalence of hyperglycaemia among adults with newly diagnosed HIV/AIDS in China. BMC Infectious Diseases. 13: 79.

41. Dave J, Lambert E, Badri M, West S, Maartens G, et al. (2011) Effect of nonnucleoside reverse transcriptase inhibitor-based antiretroviral therapy on dysglycemia and insulin sensitivity in South African HIV-infected patients. J Acquir Immune Defic Syndr 57: 284-289.

42. Polsky S, Floris-Moore M, Schoenbaum E, Klein R, Arnsten J, et al. (2011) Incident hyperglycaemia among older adults with or at-risk for HIV infection. Antivir Ther 16: 181-188.

43. Kibirige D, Ssekiteleko R, Mutebi E, Worodria W (2013) Overt DM among newly diagnosed Ugandan TB patients: cross sectional study. BMC Infectious Diseases 13: 122.

44. Salehian B, Bilas J, Bazargan M, Abbasian M (2005) Prevalence and incidence of DM among HIV-infected Minority Patients on Protease Inhibitors. Journal of the medical Association 97: 1088-1092.

45. Falutz J ( 2007) Therapy insight:body-shape changes and metabolic complications associated with HIV and highly active antiretroviral therapy. Nat Clin Prac Endocrinol Metab 3: 651-661.

46. Bacchetti P, Gripshover B, Grunfeld C, Heymsfield S, McCreath H, et al. (2005) Study of Fat Redistribution and Metabolic Change in HIV Infection (FRAM). J Acquir Immune Defic Syndr 40: 119-120.

47. Moreno S, Martinez E (2000) Lipodystrophy and long-term therapy with nucleoside reverse transcriptase inhibitors. AIDS 14: 905-906.

48. Diouf A, Cournil A, Ba-Fall K, Ngom-Guèye N, Eymard-Duvernay S, et al. (2012) Diabetes and Hypertension among Patients Receiving Antiretroviral Treatment Since 1998 in Senegal: Prevalence and Associated Factors. ISRN AIDS 5: 1-8.

49. Julius H, Basu D, Ricci E, Wing J, Basu J, et al. (2011) The burden of metabolic diseases amongst HIV positive patients on HAART attending The Johannesburg Hospital. Curr HIV Res 9: 247-252.

50. Moyo D, Tanthuma G, Mushisha O, Kwadiba G, Chikuse F, et al. (2013) Diabetes mellitus in HIV-infected patients receiving antiretroviral therapy. S Afr Med J 104: 37-39.

51. Samaras A, Burton K, Law S, Freund M, Chisholm J, et al. (2007) A syndrome of peripheral lipodystrophy hyperlipidaemia and insulin resistance in patients receiving HIV protease inhibitors AIDS 12: F51F58.

52. Ndona $\mathrm{M}$, Longo-Mbenza B, Umba B, Tsumbu Mambimbi M, Wobin $\mathrm{T}$, et al. (2012) Nadir CD4+ religion antiretroviral therapy incidence of type 2 diabetes mellitus and increasing rates of obesity among black Africans with HIV disease. International Journal of General Medicine 5: 983-990.

53. Calza L, Masetti G, Piergentili B, Trapani F, Manfredi R, et al. (2011) Prevalence of diabetes mellitus hyperinsulinaemia and metabolic syndrome among 755 adult patients with HIV-1 infection. Int J STD AIDS 22: 43-45.

54. Stanley T, Grinspoon S (2012) Body Composition and Metabolic Changes in HIV-Infected Patients. J Infect Dis 205: 223.
55. Haugaard S, Andersen O, Pedersen S (2006) Tumor necrosis factor $a$ is associated with insulin-mediated suppression of free fatty acids and net lipid oxidation in HIV-infected patients with lipodystrophy. Metabolism 55: $175-182$.

56. Carr A (2003) HIV lipodystrophy: risk factors pathogenesis diagnosis and management. AIDS 17: S141-S148.

57. Grinspoon S, Carr A (2005) Cardiovascular risk and bodyfat abnormalities in HIV-infected adults. The New England Journal of Medicine 352: 48-62.

58. Grunfeld C, Pang M, Doerrler W, Shigenaga J, Jensen P (1992) Lipids lipoproteins triglyceride clearance and cytokines in human immunodeficiency virus infection and the acquired immunodeficiency syndrome. Journal of Clinical Endocrinology and Metabolism 74: 1045-1052.

59. Guilherme A, Virbasius J, Puri V, Czech M (2008) Adipocyte dysfunctions linking obesity to insulin resistance and type 2 diabetes. Nat Rev Mol Cell Biol 9: 367-377.

60. Karpe F, Dickmann J, Frayn K (2011) Fatty Acids, Obesity, and Insulin Resistance: Time for a Re-evaluation. Diabetes 60: 2441-2449.

61. Grunfeld C (2008) Insulin Resistance in HIV infection: drugs, host responses, or restoration to health?. Topics in HIV Medicine 16: 89-93.

62. Jeroen P, Van Wijk M, Castro C (2012) Hypertriglyceridemia, Metabolic Syndrome, and Cardiovascular Disease in HIV-Infected Patients: Effects of Antiretroviral Therapy and Adipose Tissue Distribution. International Journal of Vascular Medicine 13.

63. Bastard J, Caron M, Vidal H (2002) Association between altered expression of adipogenic factor SREBP1 in lipoatrophic adipose tissue from HIV-1-infected patients and abnormal adipocyte differentiation and insulin resistance The Lancet 359: 1026-1031.

64. Brinkman K, Smeitink J, Romijn J, Reiss P (1999) Mitochondrial toxicity induced by nucleoside-analogue reverse-transcriptase inhibitors is a key factor in the pathogenesis of antiretroviral-therapy-related lipodystrophy. The Lancet 354: 1112-1115.

65. Department of Public Health and Environment (2010) Quantification of the disease burden attributable to environmental risk factors. World Health Organisation 22: 130.

66. Gervasoni C, Ridolfo A, Trifirò G, Santambrogio S, Norbiato G (1999) Redistribution of body fat in HIV-infected women undergoing combined antiretroviral therapy. HIV Aids 13: 465-471.

67. Chen D, Misra A (2002) Lipodystrophy in human immunodeficiency virus-infected patients. The Journal of Clinical Endocrinology and Metabolism 87: 4845-4856.

68. Estrada V, Portilla J (2011) Dyslipidemia related to antiretroviral therapy. AIDS Rev 13: 49-56.

69. Falutz J ( 2007) Therapy insight:body-shape changes and metabolic complications associated with HIV and highly active antiretroviral therapy. Nat Clin Prac Endocrinol Metab 3: 651-661.

70. Sullivan A, Feher M, Nelson M, Gazzard B (1998) Marked hypertriglyceridaemia associated with ritonavir therapy. AIDS 1: 1393-1394.

71. Bacchetti P, Gripshover B, Grunfeld C, Heymsfield S, McCreath H, (2005) Study of Fat Redistribution and Metabolic Change in HIV Infection (FRAM). J Acquir Immune Defic Syndr 40: 119-120.

72. Moreno S, Martinez E (2000) Lipodystrophy and long-term therapy with nucleoside reverse transcriptase inhibitors. AIDS 14: 905-906.

73. Thorogood M, Connor M, Tollman S, Lewando Hundt G, Fowkes G, et al. (2007) A cross-sectional study of vascular risk factors in a rural South African population: data from the South African Stroke Prevention Initiative (SASPI). BMC Pubic Health 7: 326.

74. Rasmussen L, Mathiesen E, Kronborg G, Pedersen C, Gerstoft J, et al. (2012) Risk of Diabetes Mellitus in Persons with and without HIV: A Danish Nationwide Population-Based Cohort Study. PLoS One 7: e44575.

75. De Wit S, Sabin C, Weber R, Worm S, Reiss P, et al. (2008) Incidence and Risk Factors for New-Onset Diabetes in HIV-Infected Patients. The Data 
Collection on Adverse Events of Anti-HIV Drugs (D:A:D). Study Diabetes Care 31: 1224-1229.

76. Wohl D ( 2007) Considering metabolic issues when initiating HIV therapy. Current HIV/AIDS Reports 4: 119-125.

77. Brown T, Cole S, Li X, Kingsley L, Palella F, et al. (2005) Antiretroviral Therapy and the Prevalence and Incidence of DM in the Multicentre AIDS Cohort Study FREE. Arch Intern Med 165: 1179-1184.

78. Martín-Timón I, Sevillano-Collantes C, Segura-Galindo A, Ar del Cañizo-Gómez FJ (2014) Type 2 diabetes and cardiovascular disease: Have all risk factors the same strength? World J Diabetes 5: 444-470.

79. Wu PY, Chen MY, Hsieh SM, Sun HY, Tsai MS et al. (2014) Comorbidities among the HIV-Infected Patients Aged 40 Years or Older in Taiwan. PLoS ONE 9: e104945.

80. Julius H, Basu D, Ricci E, Wing J, Basu J (2011) The burden of metabolic diseases amongst HIV positive patients on HAART attending The Johannesburg Hospital. Curr HIV Res 9: 247-252.

81. Ebrahim S, Pearce N, Smeeth L, Casas J, Jaffar S, et al. (2013) Tackling Non-Communicable Diseases In Low- and Middle-Income Countries: Is the Evidence from High-Income Countries All We Need? Study Diabetes Care 22: 126-142.

82. So-Armah KA, Chang J, Alcorn C, Lo Re, V Baker (2014) HIV Infection, Antiretroviral Therapy Initiation and Longitudinal Changes in Biomarkers of Organ Function. Curr HIV Res 12: 50-59.

83. Jahoor F, Gazzard B, Phillips G (1999) The acute-phase protein response to human immunodeficiency virus infection in human subjects. Am J Physiol 276: E1092-E1098.

84. Bostian KA, Blackburn BS, Wannemacher RW, Jr. McGann VG, Beisel WR (1976) Sequential changes in the concentration of specific serum proteins during typhoid fever infection in man. J Lab Clin Med 87: 577-585.

85. Grunfeld C, Pang M, Doerrler W, Shigenaga JK, Jensen P, et al. (2001) Lipids

lipoproteins triglyceride clearance and cytokines in human immunodeficiency virus infection and the acquired immunodeficiency syndrome. J Clin Endocrinol Metab 74: 1045-1052.

86. Guzik JK, Hoch NE, Brown KA, McCann LA, Rahman A, et al. (2007) Role of the $\mathrm{T}$ cell in the genesis of angiotensin IIinduced hypertension and vascular dysfunction. JEM 204.

87. Wang Y, Wang QJ (2004) The prevalence of prehypertension and hypertension among

US adults according to the new joint national committee guidelines: new challenges of the old problem. Arch. Intern. Med 164: 2126-2134.

88. Chobanian AV, Bakris GL, Black HR, Cushman WC, Green LA, et al. (2003) The

Seventh Report of the Joint National Committee on Prevention, Detection, Evaluation and Treatment of High blood pressure: the JNC 7 report. JAMA 289: 2560- 2572.

89. Lewington S, Clarke R, Qizilbash N, Peto R, Collins R (2002) Age-specific relevance

of usual blood pressure to vascular mortality: a meta-analysis of individual data for one

million adults in 61 prospective studies. Lancet 360: 1903-1913.

90. Naviar GL, Prieto-Carrasquero MC, Kobori H (2006) Molecular Aspects of the renal renin-angiotensin system. In Molecular Mechanisms in Hypertension 22: 123-125.

91. Re R, DiPette D, Schiffrin E, Sowers R (2001) Taylor and Francis, London and New York. J editors 3: 12.

92. Kim S, Iwao H (2000) Molecular and cellular mechanisms of angiotensin II-mediated cardiovascular and renal diseases. Pharmacol Rev 52: 11-34.

93. Tang KM, Wang GR, Lu P, Karas RH, Aronovitz M, et al. (2003) Regulator

of G-protein signaling-2 mediates vascular smooth muscle relaxation and blood pressure. Nat Med 9: 1506-1512.
94. Lassegue B, Clempus RE (2003) Vascular NAD(P)H oxidases: specific features, expression, and regulation. Am J Physiol Regul Integr Comp Physiol 285: R277- 297.

95. Gryglewski RJ, Palmer RM, Moncada S (1986) Superoxide anion is involved in the

breakdown of endothelium-derived vascular relaxing factor. Nature 320: 454- 456.

96. Nataraj C, Oliverio M, Mannon I, Mannon RB, Audoly PJ, et al. (1999). Angiotensin II regulates cellular immune responses through a calcineur independent pathway. J Clin Invest 104: 1693-1701.

97. American Academy of Family Physicians (2014) JNC 8 Guidelines for the Management of Hypertension in Adults. Practice Guidelines 22: 46-53.

98. Onysko J, Maxwell C, Eliasziw M, Zhang JX, Johansen N, et al. (2006) Large Increases in Hypertension Diagnosis and Treatment in Canada after a Healthcare Professional Education Program. Canadian Hypertension Control Program 23: 62-78.

99. World Health Organization (2002) The World Health Report 2002. Geneva, Switzerland: World Health Organization 20: 126.

100. Ezzati M, Lopez A, Rodgers D, Hoorn A, Murray SV, et al. (2002) Comparative Risk Assessment Collaborating Group. Selected major risk factors and global and regional burden of disease. Lancet 360: 1347-1360.

101. Margolis KL, Rolnick SJ, Fortman KK, Maciosek MV, Hildebrant CL, et al. (2005) Self-reported hypertension treatment beliefs and practices of primary care physicians in a managed care organization. Am J Hypertens 18: 566-571.

102. Mosca L, Linfante A, Benjamin H, Berra EJ, Hayes K, et al. (2005) National study of physician awareness and adherence to cardiovascular disease prevention guidelines. Circulation 111: 499-510.

103. Madhur MS, Lob HE, McCann L, Iwakura A, Blinder Y, et al. (2010) Interleukin 17 Promotes Angiotensin II-Induced Hypertension and Vascular Dysfunction. American Heart Association Journal.

104. Harrison DG, Guzik TJ, Goronzy J, Weyand C (2008) Is hypertension an immunologic disease? Curr Cardiol Rep10: 464-469.

105. Mosmann TR, Cherwinski H, Bond MW, Giedlin MA, Coffman RL (1986) Two types of murine helper T cell clone: I-definition according to profiles of lymphokine activities and secreted proteins. J Immunol 136: 2348-2357.

106. Abbas AK, Murphy KM, Sher A (1996) Functional diversity of helper T lymphocytes. Nature 383: 787-793.

107. Lafaille JJ (1998) The role of helper $\mathrm{T}$ cell subsets in autoimmune diseases. Cytokine Growth Factor Rev 9:139-151.

108. Mazzolai L, Duchosal MA, Korber M, Bouzourene K, Aubert JF et al. (2004) Endogenous angiotensin II induces atherosclerotic plaque vulnerability and elicits a Th1 response in ApoE-/- mice. Hypertension 44: $277-282$.

109. Harrington LE, Hatton RD, Mangan PR, Turner H, Murphy TL, et al. (2005) Interleukin 17-producing CD4 effector $\mathrm{T}$ cells develop via a lineage distinct from the $\mathrm{T}$ helper type 1 and 2 lineages. Nat Immunol 6:1123-1132.

110. Cheng X, Yu X, Ding Y, Fu J, Xie QQ, et al. (2008) The Th17/Treg imbalance in patients with acute coronary syndrome. Clin Immunol 127: 89-97.

111. Patel D, King N, Bailey CA, Holt SR, Venkatachalam JW, et al. (2007) Interleukin-17 stimulates C-reactive protein expression in hepatocytes and smooth muscle cells via p38 MAPK and ERK1/2-dependent NFkappaB and C/EBPbeta activation. J Biol Chem 282: 27229-27238.

112. Eid RE, Rao DA, Zhou J, Lo SF, Ranjbaran H, (2009) Interleukin-17 and interferon-gamma are produced concomitantly by human coronary artery-infiltrating $\mathrm{T}$ cells and act synergistically on vascular smooth muscle cells. Circulation 119: 1424-1432.

113. Ruddy MJ, Wong GC, Liu X, Yamamoto K, Kasayama H, et al. (2004) Functional cooperation between interleukin-17 and tumor necrosis factor- alpha is mediated by CCAAT/enhancer-binding protein family members. J Biol Chem 279: 2559-2567. 
Citation: Maseko TSB, Masuku SKS (2017) The Effect of HIV and Art on the Development of Hypertension and Type 2 Diabetes Mellitus. J Diabetes Metab 8: 732. doi:10.4172/2155-6156.1000732

Page 8 of 8

114. Guzik TJ, Hoch NE, Brown KA, McCann LA, Rahman A, et al. (2007)

Role of the $\mathrm{T}$ cell in the genesis of angiotensin II induced hypertension and vascular dysfunction. J Exp Med 204: 2449-2460. 